\title{
STRATEGI IMPLEMENTASI KEBIJAKAN PERIZINAN PADA BADAN PENANAMAN MODAL DAN PERIZINAN TERPADU KABUPATEN SUMEDANG
}

\author{
Ade Irawan \\ Fakultas Ilmu Sosial dan IImu Politik, Universitas Pasundan \\ Kota Bandung, Jawa Barat, Indonesia \\ ade.irawan@unpas.ac.id
}

\begin{abstract}
ABSTRAK
Studi ini tentang implementasi strategi perizinan dan badan perizinan terintegrasi di Kabupaten Sumedang. Pertumbuhan Pendapatan Asli Daerah Kabupaten Sumedang Jika dibandingkan dengan Anggaran Pemerintah Masih Relatif Kecil. Pertumbuhan PAD mencapai rata-rata 7 persen per tahun. Pihak BPMPT kabupaten Sumedang belum mencapai target yang ditetapkan. Hal ini dapat dilihat dari banyak fenomena yang masih belum memuaskan keluhan masyarakat atas implementasi perizinan di Kabupaten Sumedang. Metode yang digunakan adalah pendekatan studi kasus kualitatif dengan penelitian kualitatif. Teknik pengumpulan data untuk mengumpulkan data dari data primer dan data sekunder. Data primer diperoleh dari berbagai dokumen, jurnal, karya ilmiah dan lain-lain. Hasil model implementasi kebijakan yang diusulkan oleh Grindle meskipun telah dilakukan pada konten dan konteks implementasi di BPMPT Kabupaten Sumedang, terutama dalam budaya kerja.
\end{abstract}

Kata Kunci: Strategi; Implementasi Peraturan;Perizinan yang Optimal.

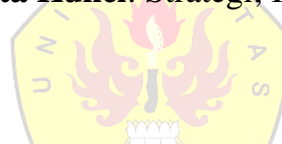

\section{ABSTRACT}

This study is about the implementation of an integrated licensing strategy and licensing agency in Sumedang District. The Growth of Sumedang Regency's Own Revenue when compared to the Goyernment Budget is still relatively small. PAD growth reaches an average of 7 percent per year. BPMPT Sumedang district has not reached the target set. This can be seen from the many phenomena that still do not satisfy public complaints about the implementation of permits in Sumedang Regency. The method used is a qualitative case study approach with qualitative research. Data collection techniques to collect data from primary data and secondary data. Primary data is obtained from various documents, journals, scientific papers and others. The results of the policy implementation model proposed by Grindle even though it has been carried out on the content and implementation context at BPMPT Sumedang Regency, especially in work culture.

Keywords: Strategy; Implementation of Regulations; Optimal Licensing.

\section{PENDAHULUAN}

Survei tahunan untuk mengukur tingkat daya saing yang dilakukan Forum Ekonomi Dunia atau World Economic Forum (WEF), yang berpusat di Geneva (Swiss) untuk The Global Competitiveness Report 2018, daya saing Indonesia berada pada peringkat ke 45, di bawah Singapura peringkat 2, dan Malaysia peringkat 25. Peringkat Indonesia mengalami penurunan dibandingkan tahun sebelumnya. Salah satu faktor penyebab adalah masih rendahnya peringkat dalam waktu pengurusan perijinan (peringkat 108), biaya awal bisnis baru (peringkat 81), dan ketidakefisienan kebijakan (peringkat 58) (Schawb, 2018). Mengatasi masalah tersebut, Pemerintah Indonesia melakukan desentrasilasi kewenangan diantaranya di bidang perizinan. Kebijakan di bidang perizinan tersebut dilakukan dengan tujuan, selain dapat meningkatkan investasi daerah juga mendorong peningkatan pendapatan daerah (Messah dan Mucai, 2012). Kebijakan publik merupakan upaya pemerintah untuk mengatasi 
masalah publik dengan membentuk undang-undang, peraturan, keputusan, atau tindakan berkaitan dengan masalah yang dihadapi (Aminu, 2012). Kabupaten Sumedang misalnya, sebagai salah satu daerah kabupaten yang juga mendapat kewenangan dalam desentralisasi atau pelaksanaan otonomi daerah, turut berperan pula dalam percepatan perizinan. Badan yang menangani Perizinan adalah Badan Penanaman Modal \& Perizinan Terpadu (BPMPT) yang dibentuk berdasarkan Perda Nomor 9 Tahun 2014 tentang Pembentukan Organisasi Perangkat Daerah Kabupaten Sumedang. Namun, berdasarkan hasil penelitian awal menunjukkan bahwa kebijakan perizinan di Badan Penanaman Modal dan Perizinan Terpadu (BPMPT) Kabupaten Sumedang belum berjalan secara efektif dan memuaskan. Hal tersebut dapat dicermati dari berbagai fenomena yaitu sebagai berikut:

1. Lambatnya proses pemberian izin dengan berbagai dalih. Kekurangan kelengkapan dokumen pendukung seperti persyaratan dari desa maupun dari kecamatan, keterlambatan pengajuan dan lainlain, alasan kesibukan tugas lain, tidak ada kejelasan dan kepastian biaya yang pasti serta tidak adanya kepastian waktu dalam penyelesaian perizinan.

2. Adanya perlakuan yang tidak sama dalam memberikan pelayanan yang berkaitan dengan pemberian perizinan. Kondisi permasalahan ini muncul sebagai konsekuensi tidak efektifnya implementasi kebijakan perizinan, sehingga jauh dari harapan publik khususnya berkaitan dengan pelayanan perizinan oleh Badan Penanaman Modal dan Perizinan Terpadu (BPMPT) Kabupaten Sumedang.

3. Ketidakstabilan politik dimana pada tahun 2014, diselenggarakannya Pemilu Legislatif dan Pemilu Presiden yang terjadi persaingan antar kompetitor baik di internal partai politik yang akan menjadi legislator maupun kompetitor antar calon presiden, sehingga investor dalam situasi seperti itu lebih memilih untuk menunggu sampai dengan proses pemilu selesai yaitu terpilih dan dilantiknya para legislator dan presiden.

4. Lemahnya sistem monitoring, pengendalian, sinergi dan konsistensi perencanaan.

Disamping itu, kendala lain dalam rangka implementasi kebijakan pelayanan perizinan pada BPMPT Kabupaten Sumedang antara lain adalah : jumlah personil/ pegawai masih kurang, profesionalisme pegawai/ petugas yang belum optimal, sarana prasarana, peralatan dan fasilitas pendukung masih terbatas, koordinasi dengan instasi terkait lainnya belum efektif, dan kendala lainnya yang bersifat teknis. Untuk mengatasi permasalahan tersebut, diperlukan suatu strategi dan implementasi kebijakan untuk meningkatkan perzininan sehingga mampu mencapai target yang telah ditetapkan serta meningkatnya kualitas pelayanan perizinan yang di lakukan Badan Penanaman Modal dan PerizinanTerpadu (BPMPT) Kabupaten Sumedang. Badan Penanaman Modal dan Perizinan Terpadu (BPMPT) adalah yang menangani 49 bidang perizinan sebagaimana pelimpahan sebagian kewenangan Bupati Sumedang melalui Peraturan Bupati Sumedang Nomor 35 Tahun 2009 yang telah direvisi dengan Peraturan Bupati Nomor 45 Tahun 2015 tentang Pelimpahan Sebagian Kewenangan Penandatanganan Perizinan dari Bupati kepada Kepala Badan Penanaman Modal dan Perizinan Terpadu (BPMPT) Kabupaten Sumedang. Lebih jauh Winarno (2002:102) dan Wahab (2008) mengatakan bahwa "implementasi kebijakan dapat dipandang sebagai alat administrasi yang merangkaikan keterkaitan antara aktor, organisasi, prosedur dan teknik yang bekerjasama untuk menjalankan kebijakan guna meraih dampak dan atau mencapai tujuan yang diinginkan”.

Penelitian ini diarahkan dalam upaya untuk mendeskripsikan implementasi kebijakan perizinan pada Badan Penanaman Modal dan Perizinan Terpadu (BPMPT) Kabupaten Sumedang yang menangani sebanyak 49 perizinan tetapi belum berjalan efektif sebagaimana diharapkan atas adanya sebuah pelayanan perizinan terpadu. Oleh karena itu, sub fokus berikutnya adalah strategi implementasi kebijakan perizinan pada Badan Penanaman Modal dan Perizinan Terpadu (BPMPT) 
Kabupaten Sumedang agar memberikan pelayanan perizinan yang efektif. Ketidakefektifan strategi implementasi kebijakan perizinan pada Badan Penanaman Modal dan Perizinan terpadu (BPMPT) Kabupaten Sumedang itu, peneliti akan melakukan penelitian berdasarkan model implementasi kebijakan dari Grindle (1980) yang terdiri dari content of policy dan context of implementation, sehingga diharapkan akan diketahui masalah ketidakefektifan implementasi kebijakan dimaksud. Penelitian ini bertujuan untuk :

1. Mengkaji dan menganalisis faktor-faktor apa yang menyebabkan implementasi kebijakan perizinan belum berjalan efektif pada Badan Penanaman Modal dan Perizinan Terpadu (BPMPT) di Kabupaten Sumedang.

2. Mengkaji dan menganalisis strategi apa yang efektif untuk mengimplementasikan kebijakan perizinan pada Badan Penanaman Modal dan Perizinan Terpadu (BPMPT) di Kabupaten Sumedang.

\section{METODE}

Metode penelitian yang digunakan adalah metode penelitian kualitatif dengan pendekatan studi kasus observasi. Penggunaan metode kualitatif, karena masalah atau problem penelitian yang ingin digali memerlukan suatu eksplorasi untuk mendapatkan pemahaman yang mendalam atas suatu fenomena, yaitu fenomena yang berkaitan dengan implementasi kebijakan di BPMPT Sumedang. Menurut Ndraha (2000 : 228) "melalui metode kualitatif peneliti mendengar dan melihat nara sumber berbicara sebenarnya (jangan dipengaruhi) tentang dirinya (mereka) sendiri sesuai dengan perspektif masing-masing”. Menurut Poerwandari (2001:12), untuk mendapatkan pemahaman yang mendalam dan khusus atas suatu fenomena serta untuk dapat memahami manusia dalam segala kompleksitasnya sebagai makhluk subjektif, maka pendekatan kualitatif merupakan metode yang paling sesuai untuk digunakan. Sumber data dalam penelitian ini adalah data primer dan data sekunder. Data primer bersumber dari lapangan yang berupa informasi dan wawancara baik dengan pejabat BPMPT Kabupaten Sumedang, beberapa camat maupun dengan masyarakat yang dianggap mengetahui dan mempunyai informasi tentang implementasi kebijakan perizinan. Data sekunder berupa data tertulis yang bersumber dari buku, dokumen, data statisik peraturan-peraturan, foto, peta yang berkaitan dan berhubungan dengan masalah implementasi kebijakan perizinan.

Analisa yang digunakan dalam penelitian ini adalah analisis SWOT dan melalui pendekatan benchmarking. Menurut Kurtz $(2008,45)$, SWOT analisis adalah suatu alat perencanaan strategi yang penting untuk membantu perencana untuk membandingkan kekuatandan kelemahan internal organisasi dengan kesempatan dan ancaman dari external. Menurut Pearce and Robinson (2003 : 134), analisis SWOT perlu dilakukan karena analisa SWOT untuk mencocokkan "fit" antara sumber daya internal dansituasi eksternal perusahaan. Pencocokkan yang baik akan memaksimalkan kekuatandan peluang perusahaan dan meminimumkan kelemahan dan ancamannya (Luis et al, 2011). Asumsi sederhana ini mempunyai implikasi yang kuat untuk design strategy yang sukses. Menurut Wheelen dan Hunger (2012 : 21), tahapan manajemen strategi terdiri dari empat tahap yaitu : analisis lingkungan, formulasi strategi, implementasi strategi, serta evaluasi dan kontrol. Benchmark adalah proses membandingkan kinerja proses bisnis dan metrik termasuk biaya, siklus waktu, produktivitas, atau kualitas yang lain secara luas dianggap sebagai tolok ukur standar industri atau praktik terbaik (Goetcsh dan Davis, 1997). Menurut Gregory H. Watson (1996), benchmarking sebagai pencarian secara berkesinambungan dan penerapan secara nyata praktik-praktik yang lebih baik yang mengarah pada kinerja kompetitif unggul.Benchmarking adalah pendekatan yang secara terus menerus mengukur dan membandingkan produk barang dan jasa, dan proses-proses dan praktik-praktiknya terhadap standar ketat yang ditetapkan oleh para pesaing atau mereka yang dianggap unggul dalam 
bidang tersebut. Dengan melakukan atau melalui benchmarking, suatu organisasi dapat mengetahui telah seberapa jauh mereka dibandingkan dengan yang terbaiknya (Goetcsh dan Davis, 1997).

\section{PEMBAHASAN}

Badan Penanaman Modal dan Perizinan Terpadu (BPMPT) Kabupaten Sumedang adalah unsur penyelenggara pelaksanaan Pemerintah Daerah di bidang perizinan yang dipimpin oleh seorang Kepala Badan yang secara fungsional bertanggung jawab kepada Bupati melalui Sekretaris Daerah Kabupaten Sumedang. Badan ini mempunyai tugas pokok membantu Bupati dalam penyelenggaraan sistem perizinan di daerah dengan fungsi melaksanakan kegiatan-kegiatan perencanaan di bidang perizinan, memberikan pelayanan perizinan, mendorong terselenggaranya perizinan yang berdaya guna dan berhasilguna, serta meningkatkan sumber Pendapatan Asli Daerah (PAD). Pelimpahan kewenangan terhadap unit kerja Kecamatan maupun ke tingkat desa belum didukung/dibarengi dengan daya dukung Sumber Daya Manusia yang memiliki kemampuan untuk itu, sehingga effisiensi penyelenggaraan perizinan belum tercapai, apalagi dikaitkan dengan tingkat kesadaran masyarakat dalam mengurus perizinan, sehingga masyarakat dimungkinkan mengeluarkan biaya yang relatif lebih besar dari tarif yang ditentukann dan sehingga masyarakat tidak tahu persis proses yang harus dilalui. Hal ini dikarenakan para pengusaha dalam mengurus peizinannya menggunakan pihak ketiga sehingga biaya yang dikeluarkan tidak sesuai dengan yang ditetapkan oleh pemerintah daerah. Tingkat kecukupan SDM baik secara kualitas maupun kuantitas belum maksimal contoh masih terbatasnya tenaga ahli kontruksi yang masih harus kerjasama dengan pihak ketiga. Hal ini mengakibatkan keterlambatan proses perizinan dikarenakan harus menunggu kerjasama dengan pihak ketiga disamping itu biaya yang harus dikeluarkan pun akan bertambah. Aktifitas pelayanan perizinan perhotelan, sebenarnya harus berdasarkan pada peraturan yang ada, namun tidak menutup kemungkinan ada penyimpangan prinsip pelayanan yang dihadapkan pada pencapaian target PAD. Dengan demikian target pencapaian target itu tidak harus menjadi sasaran utama tetapi yang menjadi sasaran utama adalah pelayanan prima. Sikap birokrasi yang memberikan informasi kepada masyarakat yang tidak jelas, seolah-olah maasyarakat harus membayar mahal melalui pihak ketiga. Aktifitas pelayanan perizinan kepariwisataan sebenarnya harus berdasarkan pada peraturan yang ada, namun tidak menutup kemungkinan ada penyimpangan prinsip pelayanan yang dihadapkan pada pencapaian target PAD, dengan demikian target pencapaian target itu tidak harus menjadi sasaran utama tetapi yang menjadi sasaran utama adalah pelayanan prima. Bahwa informasi perizinan kepariwisataan belum merata dipahami oleh masyarakat. Tahap awal proses formulasi strategi menurut David (2009) dan Kluyver \& Pearce (2006) adalah melakukan evaluasi kondisi organisasi saat ini dengan memperhatikan faktor internal dan eksternal organisasi. Dalam analisis lingkungan internal dan eksternal peneliti mengungkapkan kekuatan, kelemahan, tantangan, dan ancaman yang dihadapi Badan Penanaman Modal dan Perizinan Terpadu (BPMPT) Kabupaten Sumedang. Berdasarkan analisis lingkungan ini, dikembangkan implementasi strategi BPMPT Kabupaten Sumedang. Matriks Analisis SWOT BPMPT Kabupaten Sumedang dapat dilihat pada tabel 1.

Tabel 1. Matriks Analisis SWOT BPMPT Kabupaten Sumedang

\begin{tabular}{|l|l|l|}
\hline & Kekuatan $(\mathbf{S})$ & Kelemahan $(\mathbf{W})$ \\
$\bullet$ Memiliki badan hukum yang kuat & $\bullet$ Belum terdapat uraian tupoksi yang \\
& Letak Letak geografis yang & jelas \\
& strategis & Masih rendahnya keterpaduan \\
& mempunyai potensi sumber daya & (ego-sektoral) dan fokus beragam \\
\hline
\end{tabular}


Kebijakan: Jurnal Ilmu Administrasi

Volume 10, Nomor 2, Juni 2019

E-ISSN: 2656-2820

P-ISSN 1829-5762

\begin{tabular}{|c|c|c|}
\hline & $\begin{array}{l}\text { alam } \\
\text { - Ketersediaan institusi pendidikan } \\
\text { tinggi } \\
\text { - Potensi berbasis agro } \\
\text { - Lokasi beberapa proyek skala } \\
\text { regional dan nasional }\end{array}$ & $\begin{array}{l}\text { kebijakan dan program } \\
\text { pembangunan } \\
\text { - Masih lemahnya kerjasama dan } \\
\text { kemitraan antara lembaga iptek, } \\
\text { perguruan tinggi, pengusaha dan } \\
\text { masyarakat } \\
\text { - Terbatasnya anggaran } \\
\text { - Sarana dan prasaran belum optimal } \\
\text { - Belum dikakukan pemetaan potensi } \\
\text { setiap kecamatan }\end{array}$ \\
\hline $\begin{array}{l}\text { Peluang (O) } \\
\text { - Harapan masyarakat yang tinggi akan } \\
\text { peningkatan kualitas pelayanan } \\
\text { - Penerapan Standar Pelayanan Minimal } \\
\text { (SPM) } \\
\text { - Kualitas pelayanan mencerminkan } \\
\text { kinerja pemerintah } \\
\text { - Meningkatnya pertumbuhan } \\
\text { perekonomian terutama pada bidang } \\
\text { infrastruktur dan properti di Kabupaten } \\
\text { Sumedang } \\
\text { - Pembangunan ruas tol Cisungdawu }\end{array}$ & $\begin{array}{l}\text { Strategi SO } \\
\text { - Sosialisasi kepada masyarakat } \\
\text { - Penyediaan sistem informasi yang } \\
\text { terintegrasi seluruh kecamatan } \\
\text { - Pembinaan pelaksana } \\
\text { - Penyederhanaan prosedur } \\
\text { perizinan } \\
\text { - Mobil perizinan keliling untuk } \\
\text { menjangkau daerah yang jauh dari } \\
\text { BPMPT. } \\
\text { - Promosi potensi wilayah, } \\
\text { pariwisata, dan produk unggulan. }\end{array}$ & $\begin{array}{l}\text { Strategi WO } \\
\text { - Penyusunan GIS untuk memetakan } \\
\text { potensi wilayah di seluruh } \\
\text { Kecamatan } \\
\text { - Event untuk mendorong gairah } \\
\text { investor. } \\
\text { - Promosi potongan pajak dan } \\
\text { kemudahan investasi bagi investor. }\end{array}$ \\
\hline $\begin{array}{l}\text { Ancaman }(\mathbf{T}) \\
\text { - Perkembangan perekonomian masih } \\
\text { rendah dibanding daerah lain } \\
\text { - Jumlah pengangguran dan masyarakat } \\
\text { miskin } \\
\text { - Potensi konflik social } \\
\text { - Proses brain drain SDM potensial } \\
\text { - Persaingan yang tinggi di bidang } \\
\text { ekonomi }\end{array}$ & $\begin{array}{l}\text { Strategi ST } \\
\text { - Promosi keunggulan wilayah } \\
\text { Kabupaten Sumedang melalui } \\
\text { media cetak maupun media } \\
\text { elektronik. } \\
\text { - Pembinaan UMKM dalam } \\
\text { meningkatkan daya saing dan } \\
\text { mengurangi pengangguran. }\end{array}$ & $\begin{array}{l}\text { Strategi WT } \\
\text { - Pelatihan SDM BPMPT dalam } \\
\text { meningkatkan kinerja. } \\
\text { - Meningkatkan pengetahuan potensi } \\
\text { - wilayah BPMPT } \\
\text { - Pembangunan sarana dan prasaran. } \\
\end{array}$ \\
\hline
\end{tabular}

Dari hasil analisis lingkungan di atas dapat dipilih beberapa strategi implementasi kebijakan yang dapat digunakan oleh BPMPT Kabupaten Sumedang antara lain sebagai berikut :

1. Komitmen Bupati terhadap keberhasilan kebijakan pelayanan perizinan, sudah baik. Hal dapat dilihat dengan dibentuknya BPMPT untuk melayani semua proses perizinan, sehingga masyarakat/pengusaha cukup mendatangi satu tempat untuk mengajukan pelayanan perizinannya. Namun, Bupati juga perlu melimpahkan sebagian kewenangannya kepada camat untuk melayani beberapa perizinan, terutama yang menyangkut dengan Usaha Kecil dan Menengah (UKM), agar masyarakat tidak perlu jauh-jauh mengurusi perizinan ke BPMPT Kabupaten Sumedang.

2. Sanksi yang ditegakkan atas pelayanan perizinan sudah cukup baik, terutama dengan adanya ancaman kepada siapapun yang melanggar aturan perizinan termasuk dengan dikenakannya denda/hukuman. Namun, untuk reward/ penghargaan dirasakan masih kurang. Misalnya hadiah atau insentif bagi SOPD yang mencapai target yang dibebankan.

3. Penggunaan teknologi informasi dalam implementasi kebijakan pelayanan perizinan belum dapat digunakan secara optimal. Hal ini terjadi karena keterbatasan sumber daya manusia serta perlatan dan jaringan yang dimiliki SOPD (kecamatan).

4. Pembinaan aparat pelaksana dalam mengimplementasikan kebijakan perizinan dilakukan dengan mengikuti bimbingan teknis yang dilakukan oleh SOPD terkait dan juga melalui konsultasi kepada dinas terkait. 
5. Dalam pengimplementasian kebijakan perizinan, diperlukan dibuatkan terobosan/ penyederhanaan prosedur sepanjang tidak menyalahi aturan yang berlaku, serta dilakukannya Strategi Personal Approach (Pendekatan Personal) kepada masyarakat agar berrjalan efektif dalam mengimplementasikan perizinan.

6. Pelayanan perizinan dan pelayanan yang lainnya yang menjadi kewenangan (kecamatan) untuk memudahkan masyarakat dalam memperoleh layanan. Misalnya dengan memusatkan loket pelayanan dalam satu pintu dan juga melakukan jemput bola kepada warga yang memerlukan pelayanan

Hambatan-hambatan secara umum dalam bidang perizinan berdasarkan hasil hasil observasi dan wawancara dengan key informant dalam kebijakan perizinan di BPMPT Sumedang adalah sebagai berikut:

1. Adanya alih fungsi lahan untuk investasi memerlukan beberpa tahapan yang memerlukan waktu. Terlebih informasi tata ruang seperti RTRW apalagi RDTR, keterangan tentang tata ruang belum diketahui secara umum dan tidak mudah diakses oleh masyarakat. Demikian juga rencana strategis dan informasi tentang rencana strategis belum tersosialisasikan.

2. Belum dilakukan pemetaan potensi setiap kecamatan di Kabupaten Sumedang yang tergambar dalam Geographycal Information System (GIS) yang dapat diakses oleh masyarakat.

3. Kabupaten Sumedang juga memiliki persoalan dalam infrastruktur yang sangat terbatas sehingga akses ke berbagai pelosok belum terjangkau baik. Meskipun sekarang sedang dibangun jalan tol Cisumdawu yang nampaknya akan mempengaruhi dinamika dan pertumbuhan ekonomi Sumedang.

4. Target IMB merupakan bagian yang tidak terpisahkan dari ketidaklancaran prosedur perizinan. Hal tersebut karena adanya kecenderunngan unsur dominan terletak pada targetnya, bukan pada layanan prima dalam pengendalian pembangunan. Oleh karena itu, perizinan sebaiknya tidak dijadikan prestasi pencapaian target melainkan pelayanan prima kepada masyarakat.

5. Dibuatnya secara rutin pengukuran Indeks Kepuasan Masyarakat belum mencerminkan kondisi sesungguhnya, seperti misalnya ketepatan waktu pengelolaan izin belum sesuai waktu Pemrosesan yang sudah ditentukan.

6. Adanya tumpang tindih kewenangan antara pihak BPMPT, Kecamatan dan Kelurahan dalam hal penanganan perizinan.

Dari benchmarking pada BPTPM Kabupaten Sragen dapat menjadi best practices nasional dan pelajaran bagi BPMPT Kabupatern Sumedang, terdapat dua faktor kunci yaitu budaya yang kondusif dan motivasi keikhlasan dalam bekerja. Perbandingan model implementasi kebijakan publik menurut Grindle (1980) pada BPTPM Kabupaten Sragen dan BPMPT Kabupaten Sumedang dapat dilihat pada tabel 2.

Tabel 2.

Perbandingan Implementasi Kebijakan Publik Model Grindle Pada BPTPM Kabupaten Sragen dan Kabupaten Sumedang

\begin{tabular}{|c|l|l|l|}
\hline No & Indikator & BPTPM Kabupaten Sragen & BPMPT Kabupaten Sumedang \\
\hline 1 & Interest Affected & $\begin{array}{l}\text { Stakeholder yang berkepentingan masih } \\
\text { dalam wilayah yang wajar }\end{array}$ & $\begin{array}{l}\text { Stakeholder yang berkepentingan } \\
\text { masih dalam wilayah yang wajar }\end{array}$ \\
\hline 2 & Type of Benefits & $\begin{array}{l}\text { PAD, tertatanya tata ruang, dan kepastian } \\
\text { hukum yang jelas }\end{array}$ & $\begin{array}{l}\text { PAD, tertatanya tata ruang, dan } \\
\text { kepastian hukum yang jelas }\end{array}$ \\
\hline 3 & Extent & Kelestarian sumber daya alam, & Kelestarian sumber daya alam, \\
\hline
\end{tabular}


Kebijakan: Jurnal Ilmu Administrasi

Volume 10, Nomor 2, Juni 2019

E-ISSN: 2656-2820

P-ISSN 1829-5762

\begin{tabular}{|c|c|c|c|}
\hline No & Indikator & BPTPM Kabupaten Sragen & BPMPT Kabupaten Sumedang \\
\hline & $\begin{array}{l}\text { of Change } \\
\text { Envision }\end{array}$ & $\begin{array}{l}\text { meningkatnya antuasiame masyarakat, } \\
\text { kontrol pelaku usaha. }\end{array}$ & $\begin{array}{l}\text { meningkatnya } \text { antuasiame } \\
\text { masyarakat, kontrol pelaku industri. }\end{array}$ \\
\hline 4 & $\begin{array}{l}\text { Site of Decision } \\
\text { Making }\end{array}$ & $\begin{array}{l}\text { Berdasarkan SOP dan Keputusan Bupati } \\
\text { Sragen. Memiliki tim teknis yang } \\
\text { tergabung dalam BPTPM. }\end{array}$ & $\begin{array}{l}\text { Berdasarkan SOP No. } 63 \text { Tahun } \\
2009 \text { dan Perbup No. 55 Tahun } \\
\text { 2009. Tidak memiliki tim teknis. }\end{array}$ \\
\hline 5 & $\begin{array}{l}\text { Implementer } \\
\text { Program }\end{array}$ & $\begin{array}{l}\text { Pembagian wewenang berdasarkan } \\
\text { komponen bangunan, luas tanah dan } \\
\text { bangunan, serta lokasi bangunan. }\end{array}$ & $\begin{array}{l}\text { Pembagian wewenang berdasarkan } \\
\text { luas tanah. }<500 \mathrm{~m}^{2} \text {, izin } \\
\text { dikeluarkan kecamatan sedangkan } \\
\text { di }>500 \mathrm{~m}^{2} \text { dan berada di jalan } \\
\text { provinsi dikeluarkan BPMPT Kab. } \\
\text { Sumedang }\end{array}$ \\
\hline 6 & $\begin{array}{l}\text { Resources } \\
\text { Committed }\end{array}$ & $\begin{array}{l}\text { Proses rekrutmen pegawai sangat } \\
\text { memperhatikan aspek psikologi yaitu sikap, } \\
\text { kejujuran, dan keihlasan. } \\
\text { Usia rekrutan adalah minimal tamatan } \\
\text { SMA. Pegawai senior melatih pegawai } \\
\text { yang baru sehingga transfer knowledge } \\
\text { berlangsung dengan baik. Memiliki } \\
\text { kendaraan operasional untuk menerapkan } \\
\text { strategi jemput bola. } \\
\text { Perizinan secara elektronik, masyarakat } \\
\text { dapat melihat secara online proses } \\
\text { perizinan telah sampai di tahap mana. }\end{array}$ & $\begin{array}{l}\text { Kemampuan di bidang SDM tidak } \\
\text { mencukupi sehingga memerlukan } \\
\text { pelatihan. Terbatasnya kendaraan } \\
\text { operasional, belum memiliki } \\
\text { perizinan secara elektronik. }\end{array}$ \\
\hline 7 & $\begin{array}{l}\text { Power, Interest } \\
\text { and Strategy of } \\
\text { Actor Involved }\end{array}$ & $\begin{array}{l}\text { Jajaran pimpinan dan instansi terkait } \\
\text { memiliki komitmen yang tinggi dalam } \\
\text { memberikan pelayanan yang baik di bidang } \\
\text { perizinan. } \\
\text { Intervensi dari pihak luar dapat diredam } \\
\text { sehingga konflik bisa dihindari. } \\
\text { BPTPM berperan sebagai mediator antara } \\
\text { pihak yang bersengketa. }\end{array}$ & $\begin{array}{l}\text { Jajaran pimpinan memiliki } \\
\text { komitmen yang tinggi dalam } \\
\text { memberikan pelayana yang baik di } \\
\text { bidang perizinan. } \\
\text { Intervensi dari pihak luar cukup } \\
\text { tinggi. Dalam implementasi } \\
\text { kebijakan, terdapat } 2 \text { masalaah } \\
\text { internal yang terlibat yaitu interaksi } \\
\text { lingkungan program } \\
\text { administrasi program. }\end{array}$ \\
\hline 8 & $\begin{array}{l}\text { Institution and } \\
\text { Regime } \\
\text { Characteristic }\end{array}$ & $\begin{array}{l}\text { Menyederhanakan proses birokrasi yang } \\
\text { panjang. System satu pintu diberlakukan } \\
\text { sehingga masyarakat mengurus izin datang } \\
\text { langsung ke BPTPM. Perizinan antara } \\
\text { dinas terkait dilakukan di BPTPM karena } \\
\text { setiap dinas memiliki perwakilan. }\end{array}$ & $\begin{array}{l}\text { Belum melakukan penyederhanaan } \\
\text { proses birokrasi. System satu pintu } \\
\text { masih memiliki kendala antar dinas } \\
\text { terkait. }\end{array}$ \\
\hline 9 & $\begin{array}{l}\text { Compliance and } \\
\text { Responsiveness }\end{array}$ & $\begin{array}{l}\text { Pegawai perizinan memiliki dedikasi yang } \\
\text { tinggi dalam meningkatkan kualitas } \\
\text { pelayanan perizinan. Perbaikan } \\
\text { pelaksanaan perizinan berasal dari atas dan } \\
\text { dari bawah sehingga perbaikan dapat } \\
\text { dilakukan dengan cepat. Sosialisasi } \\
\text { dilakukan setiap minggu dengan } \\
\text { mengumpulkan masyarakat di balai desa } \\
\text { masing-masing dan media elektronik. }\end{array}$ & $\begin{array}{l}\text { Belum mampu meningkatkan } \\
\text { antusiame dan kesadaran perizinan } \\
\text { kepada masyarakat, sosialisasi di } \\
\text { bidang perizinan masih kurang, } \\
\text { masih terdapat pelaksana yang } \\
\text { tidak patuh dalam melaksanakan } \\
\text { tugasnya. }\end{array}$ \\
\hline
\end{tabular}




\section{KESIMPULAN}

Dari hasil penelitian dan analisis yang diperoleh dalam studi Strategi Implementasi Kebijakan Perizinan pada Badan Penanaman Modal dan Perizianan Terpadu Kabupaten Sumedang, dapat ditarik kesimpulan sebagai berikut :

1. Implementasi Kebijakan dalam bidang perizinan di BPMPT Kabupaten Sumedang pada dasarnya telah mencerminkan semangat dan maksud serta tujuan diselenggarakannya pelayanan terpadu ini (one stop service) meskipun belum cukup optimal. Faktor yang mempengaruhi implementasi kebijakan tersebut berdasarkan model implementasi kebijakan dari Grindle diantaranya:

a. Untuk variable konten kebijakan dari implementasi kebijakan pelayanan perizinan menunjukan bahwa dari keenam faktor yang mempengaruhi, sebagian besar tidak memiliki konflik/pertentangan yang besar pada semua faktor, mulai dari kepentingan kelompok yang terpengaruh, tipe manfaat, perubahan yang diharapkan, letak pengambilan keputusan, implementor hingga dukungan sumber daya, kecuali pada faktor sumber daya yang tersedia. Hanya pada faktor dukungan sumber daya manusia, alokasi anggaran serta implementator program yang kompeten dan kapabel yang perlu lebih dioptimalkan.

b. Untuk variable konteks implementasi kebijakan pelayanan perizinan ini menunjukkan bahwa adanya permasalahan pada faktor karakteristik institusi dan regim yang berkuasa menunjukkan bahwa permasalahan yang dihadapi pemerintah Kabupaten Sumedang seolaholah hanya menjadi tanggung jawab masing-masing sektor. Padahal penyelesaian masalah perizinan terpadu bersifat lintas sektoral dan lintas administrasi yang memerlukan komitmen serius antar sektor dan stakeholder terkait. Sedangkan faktor tingkat kepatuhan dan respon pelaksana terkendala dalam hal respon yang masih rendah dalam hal penerapan punishment terhadap pelanggar.

c. Sementara berdasarkan hasil identifikasi terhadap faktor-faktor yang mempengaruhi impelementasi kebijakan perizinan adalah :

1) Perlu adanya revisi RTRW yang ada karena sudah tidak relevan dengan kondisi dinamika perekonomian yang ada seperti zona hijau di Kabupaten Sumedang yang harus dipertahankan dan tidak boleh didirikan bangunan.

2) Perlu adanya turunan dari RTRW yaitu : RDTR (Rencana Detail Tata Ruang) untuk seluruh Kecamatan di Kabupaten Sumedang.

3) Perlu revisi Perbup Sumedang tentang RTBL terutama untuk Kecamatan Jatinangor. Hal ini dikarenakan RTBL sekarang sifatnya counter produkt dan dapat menghambat serta mengurangi minat investor menanamkan modalnya di Kabupaten Sumedang

d. Untuk faktor-faktor penghambat diantaranya adalah:

1) Di tingkat implementasi RTRW yang ada sering berjalan tidak konsisten serta informasi dan akses tentang RTRW ini sulit diketahui secara umum oleh masyarakat

2) Kondisi infrastruktur terutama jalan, fasilitas daya dukung seperti website dan kendaraan operasional yang ada belum memadai

2. Strategi implementasi kebijakan perizinan yang meliputi :

a. Sosialisasi perizinan kepada masyarakat dalam meningkatkan antusiasme dan wawasan di bidang perizinan. BPMPT Kabupaten Sumedang menyediakan mobil keliling, spanduk, media massa, media cetak maupun elektronik.

b. Penyusunan Sistem Informasi Geografi yang memetakan potensi wilayah, peruntukan wilayah, dan rancangan tata ruang yang dapat diakses oleh msyarakat. 
c. Pelatihan SDM, penyederhanaan prosedur perizinan, dan perizinan elektronik untuk meningkatkan kinerja dan kecepatan perizinan.

d. Penerapan reward and punishment di bidang perizinan. Reward berupa Tunjangan Penambahan Penghasilan (TPP). Punishment berupa mutasi dan penundaan gaji berkala.

e. Pemindahan lokasi kantor BPMPT Kabupaten Sumedang ke bekas kantor DPPKAD yang lokasinya di Jalan Parbu Geusan Ulun.

f. Rekruitment berdasarkan psikotes dan disediakan motivator untuk pembentukan karakter petugas BPMPT Kabupaten Sumedang.

\section{DAFTAR PUSTAKA}

Aminu, Tella, dan Mbaya. 2012. Public Policy Formulation and Implementation in Nigeria. Jurnal internasional Public Policy and Administration Research Vol.2, No.5

David, Fred. R. 2009. Strategic Management : Concepts. Alih Bahasa oleh Kresno Saroso. Prentice Hall. New Jersey.

Grindle, Merilee S. 1980. Politics and Policy Implementation in the Third World. New Jersey : Unity Press.

Goetsch, David L. dan Stanley B. Davis. 1997. Total Quality Management, diterjemahkan oleh Benyamin Molan. Total Kualitas Mana:iemen. Jakarta: Prenhallindo.Ndraha, Taliziduhu. 1999. Pengantar Teori Pengembangan Sumber Daya Manusia. Jakarta : Rineka Cipta.

Kluyver, C. A. \& Pearce II, J. A. 2006. Strategy: A View from the Top, 2nd Edition,. Upper Saddle River, NJ: Pearson Prentice Hall.

Luis E. Kurtz, Boone, David L. 2011. Pengantar Bisnis Kontemporer. Búku 2. Salemba Empat, Jakarta.

Messah dan Mucai. 2012. Factors Affecting the Implementation of Strategic Plans in Government Tertiary Institutions: A Survey of Selected Technical Training Institutes. Jurnal European Journal of Business and Management Vol 3, No.3.

Pearce II, John A. dan Robinson Richard B.Jr. 2003. Manajemen Strategis 10. Salemba Empat, Jakarta

Peraturan Bupati Sumedang Nomor 45 Tahun 2015 tentang Pelimpahan Sebagian Kewenangan Penandatanganan Perizinan dari Bupati kepada Kepala Badan Penanaman Modal dan Perizinan Terpadu (BPMPT) Kabupaten Sumedang .

Peraturan Daerah Nomor 9 Tahun 2014 tentang Pembentukan Organisasi Perangkat Daerah Kabupaten.

Poerwandari. 2001. Pendekatan Kualitatif dalam Penelitian Psikologi. Jakarta : Lembaga Pengembangan Sarana Pengukuran dan Pendidikan Psikologi. Fakultas Psikologi Universitas Indonesia.

Schwab, Klaus. 2018. The Global Competitiveness Report 2018. World Economic Forum.

Wahab, Solihin Abdul. 2008. Analisis Kebijakan, dari Formulasi ke Implementasi Kebijakan Negara. Jakarta : Bumi Aksara.

Watson, Gregory. 1996. Strategic Benchmarking. Jakarta : PT Gramedia.

Winarno, Budi. 2002. Teori dan proses Kebijakan Publik. Yogyakarta : Mediapress.

Wheelen, Thomas 1. Hunger, J.David. 2012. Manajemen Strategis, Edisi Kelima,. Andi,Yogyakarta 